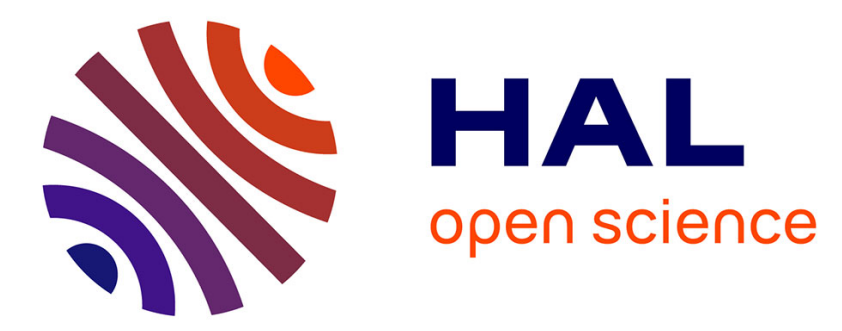

\title{
Improvements for imaging ceramics sintering in situ in ESEM
}

\author{
Lucile Joly-Pottuz, A. Bogner, A. Lasalle, Annie Malchere, G. Thollet, S. \\ Deville
}

\section{- To cite this version:}

Lucile Joly-Pottuz, A. Bogner, A. Lasalle, Annie Malchere, G. Thollet, et al.. Improvements for imaging ceramics sintering in situ in ESEM. Journal of Microscopy, 2011, 244 (1), pp.93-100. 10.1111/j.1365-2818.2011.03512.x . hal-00639510

\section{HAL Id: hal-00639510 https://hal.science/hal-00639510}

Submitted on 4 May 2018

HAL is a multi-disciplinary open access archive for the deposit and dissemination of scientific research documents, whether they are published or not. The documents may come from teaching and research institutions in France or abroad, or from public or private research centers.
L'archive ouverte pluridisciplinaire HAL, est destinée au dépôt et à la diffusion de documents scientifiques de niveau recherche, publiés ou non, émanant des établissements d'enseignement et de recherche français ou étrangers, des laboratoires publics ou privés. 


\title{
Improvements for imaging ceramics sintering in situ in ESEM
}

\author{
L. Joly-Pottuz ${ }^{1,2}$, A. Bogner ${ }^{1,2^{*}}$, A. Lasalle ${ }^{3}$, A. Malchere ${ }^{1,2}$, G. Thollet ${ }^{1,2}$, S. Deville ${ }^{3}$ \\ ${ }^{1}$ Université de Lyon, France \\ ${ }^{2}$ INSA de Lyon, MATEIS UMR CNRS 5510, 7 Avenue Jean Capelle, 69621 \\ Villeurbanne, France \\ ${ }^{3}$ Laboratoire de Synthèse et de Fonctionnalisation des Céramiques, UMR 3080 \\ CNRS/Saint-Gobain CREE, 550 Avenue Alphonse Jauffret, BP 20224, 84306 \\ Cavaillon Cedex, France
}

Keywords: ESEM, high-temperature, in-situ, sintering, ceramics

\begin{abstract}
Sintering of green samples of alumina produced by ice-templating was followed in-situ in an environmental scanning electron microscope (ESEM) up to temperatures as high as $1375^{\circ} \mathrm{C}$. These alumina samples with well-defined architectures are of great interest in the field of materials science due to their high specific strength (especially in compression), low density and adaptable porosity. For the present study, they also have the advantage to exhibit an important topography, inducing interesting contrast when imaged in ESEM. Improvements of the imaging conditions in ESEM were essential to really follow the sintering process involving formation of necks between grains or shift of the center of grains. This paper describes the improvements made and the results observed on the sintering process of alumina green samples processed by ice-templating.
\end{abstract}

\section{Introduction}

Using ice as a templating agent is a novel processing strategy to synthesize porous and highly textured ceramics (Deville, 2006)-(Munch, 2008). Studies are conducted to better understand how ceramics slurries behave during the ice-templating process. This approach is a way to improve the final structure via the control of the green samples structure (Zou, 2009)- (Deville, 2010), but the control of the sintering process is also essential as it influences the density of ceramic walls, the porosity and so the properties of the final material which determine its potential for future applications. The sintering 
mechanisms can be investigated through the observation of sintered ceramics at different steps of the sintering process. Another and more direct way is by following the structure changes of the sample during heating. Environmental scanning electron microscope (ESEM) allows such dynamic study during heating: the sintering of ceramics can be performed in-situ inside the ESEM. Indeed, this approach allows heating the sample at high temperatures, thus studying the sintering process of the powder with a resolution good enough to follow the grain behavior (shift, coalescence, etc). Furthermore, alumina green samples synthesized by ice-templating present a complex structure composed of lamellae. To follow the evolution of the whole sample, the evolution of both lamellae and grains inside the lamellae must be studied. By using several magnifications inside the ESEM, both evolutions can be followed. With TEM technique, even if the resolution would be better to follow the grains, the sample could not be bulk: the sample preparation would be very delicate since green samples are too brittle to obtain a thin foil. Moreover, the heating stage should allow a homogeneous heating of the whole sample.

High temperature experiments inside an ESEM are not straightforward. Few studies in the literature report experiments of heating inside a scanning electron microscope. Srinivasan et al. studied the evolution of the structure and the morphology of iron powder in an ESEM up to $1123{ }^{\circ} \mathrm{C}$ (Srinivasan, 2002). Sintering of copper particles with an original system which allows to apply force on particles during sintering was performed (Smith, 2006). Concerning ceramic materials, the behavior of refractory castables under high temperature was followed inside in ESEM up to $1300^{\circ} \mathrm{C}$ (Marzagui, 2004). Subramaniam et al. studied the sintering process of $\mathrm{BaTiO}_{3}$ at magnifications $5 \mathrm{k}$ and $10 \mathrm{k}$ with a heating up to $1300^{\circ} \mathrm{C}$ (the biggest spot size was used to keep an important signal level, but it induced a lost of resolution) (Subramaniam, 2006). Nevertheless, no study at higher temperatures and magnification was reported. Above a temperature of $1300^{\circ} \mathrm{C}$, thermal emission becomes a serious problem. Imaging becomes very difficult because contrast and signal to noise ratio of images is degraded. In this work, the imaging conditions were optimized to perform the sintering of alumina green samples produced by ice-templating and to follow the evolution of the samples in-situ during heating up to $1375^{\circ} \mathrm{C}$ and at magnification as high as 40k. Several experimental conditions were studied (material of the crucible used, nature and pressure of the chamber environment, beam spot size, sample and thermal shield biases) in order to obtain images on which grain sizes, grain shifts and densification of the samples could be followed. Images were recorded at several magnifications in order to follow both the general evolution of the sample (evolution of the lamellae) and the evolution at the grain scale. After optimization of the imaging conditions, the shrinkage obtained by heating the sample in different atmospheres was studied in order to determine if the environment used could have an influence on the structure obtained and to correlate in-situ experiments and classical ex-situ sintering process. 


\section{Materials and methods}

Preliminary observations were made on samples of $\mathrm{ZnO}$ powder - its sintering is indeed easier to observe as it occurs at relatively low temperature - and on TM-DAR green samples synthesized by slip-casting. Then green samples of two $\alpha$-alumina powders: TM-DAR (Taimei Chemicals, Tokyo, Japan) and Ceralox SPA 0.5 (Sasol North America Inc., Tucson, AZ) produced by ice-templating were observed and heated. The mean grain size of the TM-DAR powder is $100-200 \mathrm{~nm}$, resulting in a sintering temperature around $1250^{\circ} \mathrm{C}$. The mean grain size of the Ceralox powder is $400 \mathrm{~nm}$ with a sintering temperature of $1450^{\circ} \mathrm{C}$. Samples produced by ice-templating present a lamellar structure (figure 1) which induces interesting topographic contrast.

Green samples subject to "classical" sintering in air (performed ex-situ in an oven) were also observed inside the microscope. The aim was to compare these structures with the ones of samples sintered inside the microscope. The ex-situ heating cycle was as follows: first, a binder burnout in two steps : heating at $50^{\circ} \mathrm{C} / \mathrm{h}$ from $20^{\circ} \mathrm{C}$ to $490^{\circ} \mathrm{C}$, isotherm at $490^{\circ} \mathrm{C}$ for $1 \mathrm{~h}$, heating at $30^{\circ} \mathrm{C} / \mathrm{h}$ from $490^{\circ} \mathrm{C}$ to $550^{\circ} \mathrm{C}$, isotherm at $550^{\circ} \mathrm{C}$ for $30 \mathrm{~min}$ and then the sintering step heating at $300^{\circ} \mathrm{C} / \mathrm{h}$ from $550^{\circ} \mathrm{C}$ to $1425^{\circ} \mathrm{C}$, and isotherm for $1 \mathrm{~h}$ at $1425^{\circ} \mathrm{C}$ for samples prepared with Ceralox powder and at $1250^{\circ} \mathrm{C}$ for TMDAR.

In-situ experiments were performed in an FEI XL 30 FEG ESEM equipped with a heating stage allowing heating the sample up to $1500^{\circ} \mathrm{C}$. A scheme of the device is presented in figure 2. A gaseous secondary electrons detector (GSED) was used to collect the signal. A thermal shield was placed between the heating stage and the GSED to prevent damage of the detector from infrared radiations and also to ensure a better regulation of the temperature of the sample. This shield can be positively biased (from 0 up to $300 \mathrm{~V}$ ). The crucible containing the sample can be biased from -46 to $46 \mathrm{~V}$. These biases can be changed during the experiments to optimize the contrast and brightness of images.

Imaging was optimized in the following conditions: high voltage at $30 \mathrm{kV}$, spot size 4 at low temperature and 5 at higher temperature, gas pressure around 2-3 Torr and working distance of $20 \mathrm{~mm}$. The working distance used in this work was the minimal distance possible with our system to avoid a contact between the heating stage and the thermal shield (see figure 2). The gas pressure was also optimized in situ at this working distance in order to have a good compromise between enough SE signal amplification and acceptable signal to noise ratio. 
A thin foil of the green sample was cut with a razor blade. The thinnest foil is chosen in order to insure a good thermal conductivity between the crucible and the sample. We can assume that the surface of the sample is at the same temperature than the crucible. Thus the surface represents the whole structure evolution.

First, a crucible made of $\mathrm{MgO}$ and covered with a Pt layer, available with the heating stage, was used. Then, to enhance the signal and contrast of the images, a new homemade crucible made of platinum (90\% Pt-10\% Rh) was used.

The measurement of the temperature was calibrated for the use of the commercial $\mathrm{MgO}$ crucible. Thus, it was necessary to calibrate the system with the Pt one to be sure to have a good measurement of the temperature. For this experiment, a thermocouple was directly placed in the crucible wall (in a small hole) and the temperature was been followed during a heating experiment. A calibration curve was plotted and shown that the temperature is very close to the setting temperature in the range $200-1400^{\circ} \mathrm{C}$.

Three different gases were tested: water, $\mathrm{N}_{2}$ (Linde Gas 5.0) and dry air (Alphagaz 1).

The ex-situ heating cycle duration is more than 24 hours due to the low heating rates chosen. The in-situ heating cycle was chosen so that the duration of one experiment does not exceed 10 hours for sake of security. It is started by heating at $50^{\circ} \mathrm{C} / \mathrm{min}$ from $20^{\circ} \mathrm{C}$ to $490^{\circ} \mathrm{C}$. Then the heating rate was decreased at $5^{\circ} \mathrm{C} / \mathrm{min}$ from $490^{\circ} \mathrm{C}$ to $550^{\circ} \mathrm{C}$ to follow the binder and dispersant burnout. After this step, a relatively low heating rate of $20^{\circ} \mathrm{C} / \mathrm{min}$ was chosen in order to be able to follow the evolution of the sample. Then, if required, XRD analyses of sintered samples were performed ex-situ with a Bruker diffractometer ( $\mathrm{Cu}$ anticathode, $\left.\lambda_{\text {cu }} 1.54060 \AA\right)$.

\section{Results and discussion}

\subsection{Optimization of the experimental conditions}

As mentioned previously, several parameters can affect imaging conditions: bias of sample and thermal shield, spot size of the beam, nature of crucible used, nature and pressure of gas used in the chamber, working distance, etc.

Both the sample and the shield can be biased: a positive bias of the shield improves the signal by attracting electrons in the direction of the GSED detector; a negative bias of the sample also improves the signal since electron emission from the sample is easier. Thus, at low temperature, a negative bias of the sample and a positive bias of the shield were used. But at high temperature, thermionic emission becomes too 
significant, and a positive bias of the sample can be necessary to restrain the thermionic emission. Unfortunately, secondary electrons present the same energy range than thermionic electrons and are also retained by the sample. In that case, only backscattered electrons can be collected by the GSED and images obtained have a zcontrast and not a topographic one.

Spot size of the beam chosen for the observation also affects imaging. To improve the resolution, the spot size must be reduced. But by reducing the spot size, the signal is also reduced. In fact, the spot size must be chosen large enough to have signal but small enough to keep a sufficient resolution.

The first experiments were performed with the $\mathrm{MgO}$ crucible and revealed that the nature of the crucible can also affect imaging. By using this crucible, a quick loss of signal of the images from $900-1000^{\circ} \mathrm{C}$ was observed. Even with contrast enhancement, it was not possible to follow grain rearrangement or grain coalescence during sintering. This loss of signal can be explained by the thermionic emission from the sample holder and the sample, blurring the image. Thermionic electrons emitted have the same energy than secondary electrons and thus both types of electrons are collected (figure 3).

The thermionic emission can be described by the Richardson-Dushman law where $J$ is the emission current density $\left(\mathrm{A} / \mathrm{m}^{2}\right), \Phi$ is the work function of the metal and $\mathrm{A}$ is the Richardson constant:

$$
J=A T^{2} \exp \left(-\frac{\varphi}{k T}\right)
$$

From this equation, it appears that one way to limit the thermionic emission is to use a material with a high work function for the crucible. Platinum is the best compromise with high work function and melting temperature. Polycrystalline platinum has a work function equal to $5.64 \mathrm{eV}$ (Weast,1981). Lim et al. determined the work function of $\mathrm{MgO}$ single crystal at several orientations (111), (200) and (220) to be respectively equal to $4.22 \mathrm{eV}, 4.94 \mathrm{eV}$ and $5.07 \mathrm{eV}$ (Lim, 2003). For a polycrystalline MgO sample, the work function can be estimated as an average of these three values i.e. $4.7 \mathrm{eV}$. By changing the $\mathrm{MgO}$ crucible into a $\mathrm{Pt}$ one, we can expect a limitation of the thermionic emission (figure 4). This is confirmed by a calculation of the thermionic emission from $\mathrm{MgO}$ and $\mathrm{Pt}$, which shows that thermionic emission from $\mathrm{Pt}$ will become important only from $1200^{\circ} \mathrm{C}$, instead of $1000^{\circ} \mathrm{C}$ in the case of the $\mathrm{MgO}$ crucible. These results are in good agreement with the observations performed in the microscope during in-situ sintering. With the $\mathrm{MgO}$ crucible, signal is lost at $1050^{\circ} \mathrm{C}$. With the $\mathrm{Pt}$ crucible, images obtained at $1300^{\circ} \mathrm{C}$ still exhibit a good signal allowing the observation of changes of the sample. It is important to notice that the bottom of the $\mathrm{MgO}$ crucible was covered with a Pt layer. But this layer was too thin and not homogeneous, thus not preventing thermionic emission. 
A comparison of images obtained at a temperature of $900^{\circ} \mathrm{C}$ with the two kinds of crucibles confirms that better images are obtained with the Pt crucible (see figure 5). In the case of the $\mathrm{MgO}$ crucible (figure 5a), even after contrast enhancement of the image, it was not possible to observe changes of the grain. In the case of the Pt crucible, good quality images were obtained and it was possible to observe the grains (figure $5 b)$. Furthermore, the grain sizes of the powder observed with the Pt crucible $\left(\mathrm{Al}_{2} \mathrm{O}_{3}\right.$ green samples obtained by slip-casting) was smaller than the one of the powder observed with the $\mathrm{MgO}$ crucible ( $\mathrm{ZnO}$ powder). These examples clearly prove the interest of using a $\mathrm{Pt}$ crucible to improve imaging at high temperature.

Another parameter checked in order to improve imaging is the nature of the gas used in the chamber during the experiment. We investigated three gases: water -the most common gas used in ESEM-, $\mathrm{N}_{2}$ and dry air in order to be closer to the ex-situ sintering conditions. Figure 6 presents images obtained with the three gases at several temperatures. During the experiments, bias of both the sample and the thermal shield was changed to optimize imaging. With the three gases, a loss of signal is observed when heating the sample. However, water is the only gas which allows observing the sample at $1300^{\circ} \mathrm{C}$. In the case of $\mathrm{N}_{2}$, it is difficult to obtain good quality images at $1250^{\circ} \mathrm{C}$ (see figure $6 \mathrm{f}$ ). With dry air, at $1050^{\circ} \mathrm{C}$ the signal becomes weak (see figure $6 \mathrm{~h}$ ). At $1200^{\circ} \mathrm{C}$, the sample was positively biased in order to keep the thermionic electrons away from the detector (otherwise the detector was saturated). But a lot of secondary electrons with the same energy as the thermionic ones were not collected either. Thus the image was obtained by collecting backscattered electrons and corresponds to a chemical contrast and not a topographic one. With this kind of images, it is not possible to follow the evolution of the grains. Results obtained with water were not surprising and several studies have already been described in the literature to compare the performances of gases. Fletcher et al. studied the amplification signal of water compared to nitrogen and other gases (Fletcher, 1997). They conclude that water presents the best signal amplification due to the ionization properties of the gas. In the case of dry air, electric discharges can occur during observation. They occur at high temperature and must be avoided since they can damage the microscope device. Results obtained in the present study clearly indicate that water is the most efficient gas to reach good and stable imaging conditions.

\section{2- Study of densification}

During in-situ sintering, images at several magnifications were recorded. Images at low magnification of one platelet (see figure 7) were used to follow the densification of the green samples during heating. For the experiments performed in water, the evolution was followed from ambient temperature up to $1375^{\circ} \mathrm{C}$. In the case of dry air, the 
evolution was followed up to $1050^{\circ} \mathrm{C}$, then the sample was heated up to $1300^{\circ} \mathrm{C}$ or $1450^{\circ} \mathrm{C}$ without imaging, and images were recorded during cooling of the sample (at $400^{\circ} \mathrm{C}$ after heating at $1300^{\circ} \mathrm{C}$ and at ambient temperature after heating at $1450^{\circ} \mathrm{C}$ ). Results obtained on the shrinkage for both environments are summarized in tables 1 and 2 .

In the case of green samples sintered in a water environment (table 1), a dilatation of the sample due to increasing temperature was observed first until $1000^{\circ} \mathrm{C}$, followed by a shrinkage. To evaluate the total shrinkage, measurements were performed on images at ambient temperature before and after heating: it was estimated at 7-8\%. This low value can be explained by the short holding time at $1284^{\circ} \mathrm{C}$ during the experiment. Experiment at higher temperature shown a small evolution of the shrinkage up to $9 \%$. In dry air, as for the water environment, a dilatation of the sample was observed first, followed by a shrinkage. After sintering at $1300^{\circ} \mathrm{C}$, the total shrinkage observed at $400^{\circ} \mathrm{C}$ was equal to $7 \%$. Considering that the shrinkage would be a little bit more pronounced at ambient temperature, we can conclude that the same shrinkage was obtained with water and dry air. After heating at $1450^{\circ} \mathrm{C}$, a shrinkage of $11 \%$ was observed.

After the sintering process of the Ceralox powder under a water environment, a glassy surface was observed (figure 8a). It seemed that a compound was covering the surface since it was not possible to distinguish grains anymore. Our first assumption was the formation of boehmite due to the reaction between water and alumina. But the same experiment in a $\mathrm{N}_{2}$ environment led to the same surface aspect of the sample (figure 8b). X-Ray diffraction of the two samples confirmed that the surface was not covered with boehmite (figure 9) as characteristic peaks of boehmite (at $15^{\circ}, 28^{\circ}, 38^{\circ}$ ) were not observed (JCPDS 01-074-1895). Peaks observed were characteristic of $\alpha$-alumina, except one peak at $21^{\circ}$, corresponding to $\mathrm{AlPO}_{4}$ (JCPDS 011-0500) and only observed in the case of Ceralox powder.

From these results, it seems that Ceralox powder with a sintering temperature higher than the TM-DAR powder reacts with a compound inside the chamber of the microscope at high temperature. At this temperature, the TM-DAR powder is already sintered and thus less reactive: it does not react with this compound. Subramaniam et al. found the presence of $\mathrm{Al}\left(\mathrm{H}_{2} \mathrm{PO}_{4}\right)_{3}$ in the heating jacket of their heating stage (Subramaniam, 2006) which led to the release of phosphate inside the chamber during sintering. In our study, a piece of the heating jacket of the heating stage used in this study was analyzed by XRD. This analysis confirmed the presence of $\mathrm{AlPO}_{4}$ and the assumption of a reaction between the powder and a compound present in the microscope chamber. The heating jacket of our heating stage has to be changed in order to perform heating experiment at very high temperatures. In our case, as the 
TM-DAR powder does not react with the phosphate compound, it means that the release of phosphate occurred above the TM-DAR sintering temperature (i.e. above $1250^{\circ} \mathrm{C}$ ). This temperature does not match with Subramaniam's experiments. It is important to notice that the heating stages of new generation ESEM seem to present new jackets of stable alumina, avoiding such contamination problems.

The dynamic observation of the Ceralox powder sintering was not possible because of the formation of the phosphate compound which completely covered the sintered materials. But this did not occur in the case of the TM-DAR powder where the following of the sintering process was possible. With the water environment, the formation of necks was observed between grains (figure 10a). In this case, the sintering occurred with diffusion of atoms from the surface. This led to formation of necks between grains but the centers of grains do not move. No densification was observed. The maximum shrinkage was equal to $7 \%$. With the dry air environment, the diffusion of atoms occurred from the grain volume or from grain boundaries. This mechanism led to a densification of the ceramics (figure 10b). These results are in good agreement with the ones obtained in (Chinelatto, 2009). Our in-situ sintering experiments confirm the sintering mechanisms already observed on $\alpha$-alumina.

However, it was not always straightforward to correlate sintering experiments performed in-situ inside the microscope and sintering experiments performed ex-situ in a classical oven used to prepare ceramics materials. Indeed, the heating cycle was not exactly the same as the one used for "classical" sintering for experiments inside the microscope. The reason is that the corresponding thermal cycle is too long to ensure security of such experiment in an ESEM (present experimental conditions are at the limit of the temperature range for the device). Final shrinkage obtained with "classical" sintering was equal to $18 \%$. Inside the microscope the shrinkage observed was between 7 and $11 \%$. This discrepancy can be explained by the difference of heating cycles and the duration of heat treatments of both experiments. Nevertheless, sintering process was observed inside the ESEM: it is the only technique allowing a direct observation of the evolution of the sample during heat treatment, with the resolution of a SEM.

\section{Conclusions}

The improvement of imaging conditions allowed performing in-situ observations at high temperature, above $1375^{\circ} \mathrm{C}$, inside an ESEM. The use of a platinum crucible led to an increase of signal and contrast, essential for the present study. Other parameters (bias of sample and thermal shield, spot size of the beam and environment) were also proved to affect imaging. In terms of environment, with $\mathrm{N}_{2}$ or dry air, the image signal was lost at $1200^{\circ} \mathrm{C}$ and $1050^{\circ} \mathrm{C}$ respectively. Furthermore, with dry air electric discharges occurred during observation. Water was found to be the most efficient gas, as already 
observed in other studies in the literature. The water environment allowed imaging up to $1375^{\circ} \mathrm{C}$. The shrinkage obtained was a function of the chamber environment used, thus correlation between in-situ experiments and classical sintering were not straightforward. However, the study of the shrinkage obtained by heating the sample in water or dry air was in agreement with others studies of alumina sintering, and allowed the description of the different sintering mechanisms. The results of the present study are promising: heating experiments with a Pt crucible are possible at temperature as high as $1375^{\circ} \mathrm{C}$. Moreover, with the use of the heating stage available in the new generation of ESEM, and the higher beam current in these microscopes, we can expect that satisfying experiments would be possible up to $1500^{\circ} \mathrm{C}$.

\section{References}

Deville, S., Saiz, E., Nalla, R.K., Tomsia, A.P. (2006) Freezing as a path to build complex composites. Science 311, 515-518.

Munch, E., Launey, M.E., Alsem, D.H., Saiz, E., Tomsia, A.P., Ritchie, R.O. (2008) Tough, Bio-Inspired Hybrid Materials. Science 322, 1516-1520.

Zou, J., Zhang, Y., Li, R. (2009) Effect of Suspension State on the Pore Structure of Freeze-Cast Ceramics. International Journal of Applied Ceramic Technology 8, 1-8.

Deville, S., Maire, E., Lasalle, A., Bogner, A., Gauthier, C., Leloup, J., Guizard, C. (2010) Influence of Particle Size on Ice Nucleation and Growth During the IceTemplating Process. Journal of the American Ceramic Society 93, 2507-2510.

Srinivasan, N. S. (2002) Dynamic study of changes in structure and morphology during the heating and sintering of iron powder. Powder Technology 124, 40-44.

Smith, A. J. (2006) Use of a micromanipulator at high temperature in an environmental scanning electron microscope to apply force during the sintering of copper particles, Scripta Materialia 55, 707-710.

Marzagui, H. (2004) Characterisation of microstructural evolutions in refractory castables by in situ high temperature ESEM, Journal of Materials Processing Technology 155-156, 1474-1481.

Subramaniam, S. (2006) In situ high temperature environmental scanning electron microscopic investigations of sintering behavior in barium titanate. $\mathrm{PhD}$ Thesis, University of Cincinnati.

Deville, S. (2008) Freeze-casting of porous ceramics: A review of current achievements and issues. Advanced Engineering materials 10, 155-169.

Weast, R.C. (1981) Handbook of Chemistry $62^{\text {nd }}$ edition, CRC Press.

Lim, J.Y., Uhm, H.S., Choi, E.H. (2003) Work function of $\mathrm{MgO}$ single crystals from ion-induced secondary electron emission coefficient. Journal of Applied Physics 94-1, 764-769. 
Fletcher, A.L., Thiel, B.L., Donald, A.M. (1997) Amplification measurements of potential imaging gases in environmental SEM. J. Phys. D 30, 2249-2257.

Chinelatto, A.S.A., Tomasi, R. (2009) Influence of processing environment on the microstructural evolution of submicron alumina powder during sintering. Ceramics International 35, 2915-2920.

\section{Acknowledgements:}

The authors would like to acknowledge two INSA-Lyon SGM department students C. Alaux and N. Herrbach for their training work, and the CLYM for the access of the FEI XL-30 FEG ESEM. Financial support was provided by the National Research Agency (ANR), project NACRE in the non-thematic BLANC programme, reference BLAN07-2_192446.

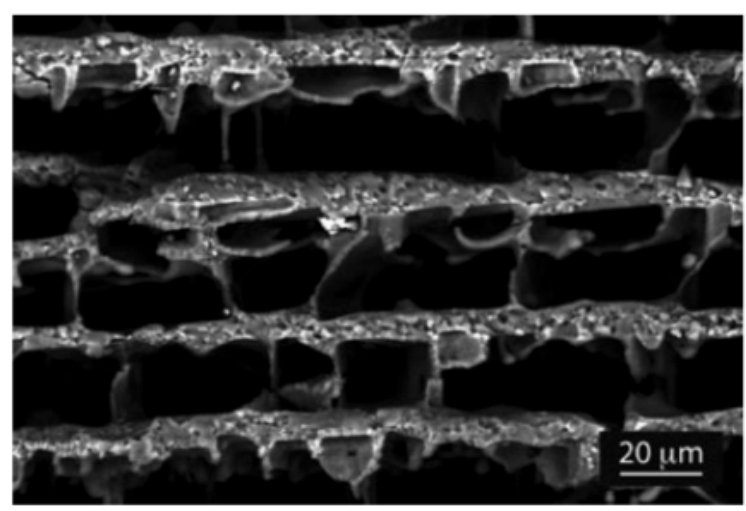

Fig. 1. Structure of the alumina green samples synthesized by ice- templating (Deville, 2008).

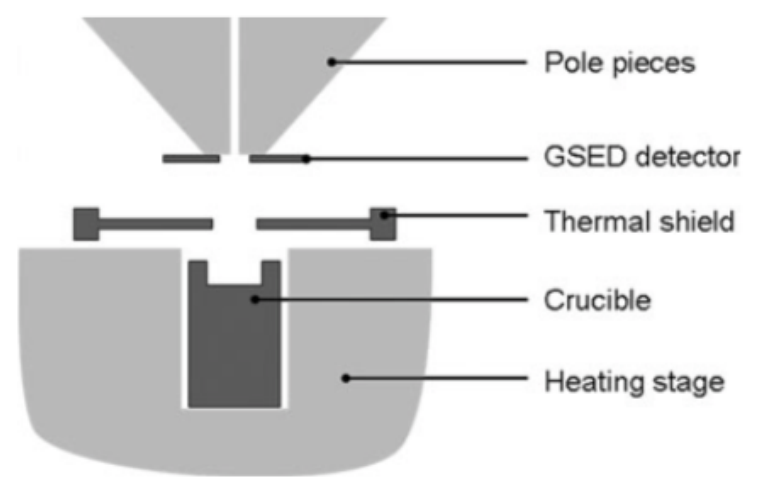

Fig.2. Scheme of the experimental device used in the ESEM. 


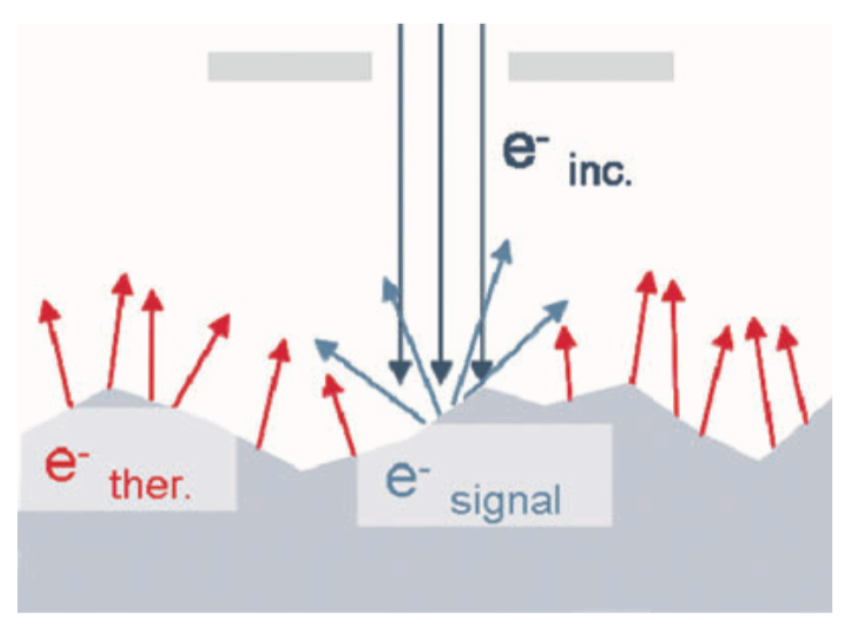

Fig. 3. Scheme of the thermionic emission. Thermionic electrons have the same energy than secondary electrons.

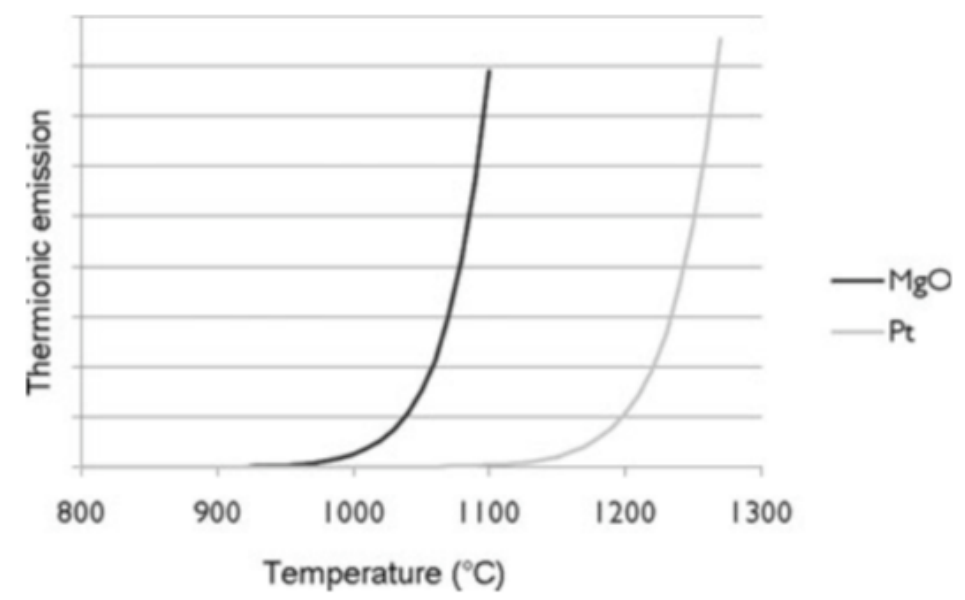

Fig. 4. Thermionic emission of $\mathrm{MgO}$ and Pt calculated with the RichardsonDushman relation.
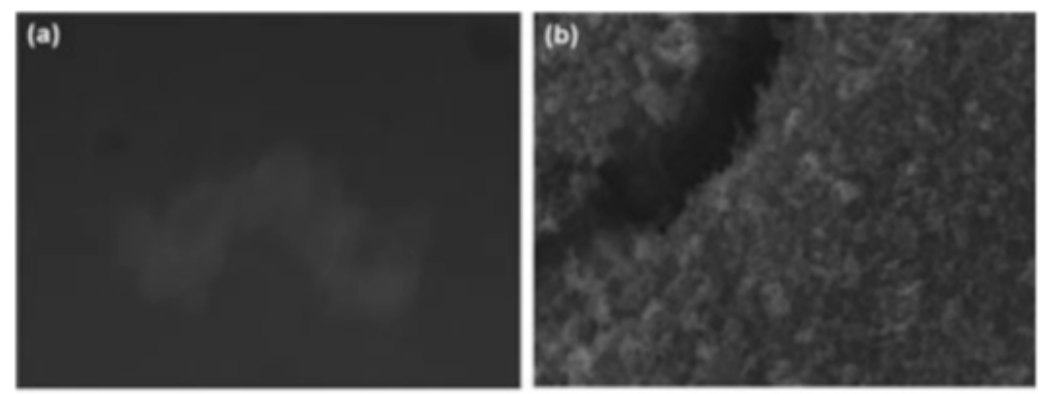

$$
5 \mu \mathrm{m}
$$

Fig. 5. Comparison of images obtained at $900^{\circ} \mathrm{C}$ with (a) the $\mathrm{MgO}$ crucible and (b) the Pt crucible. 

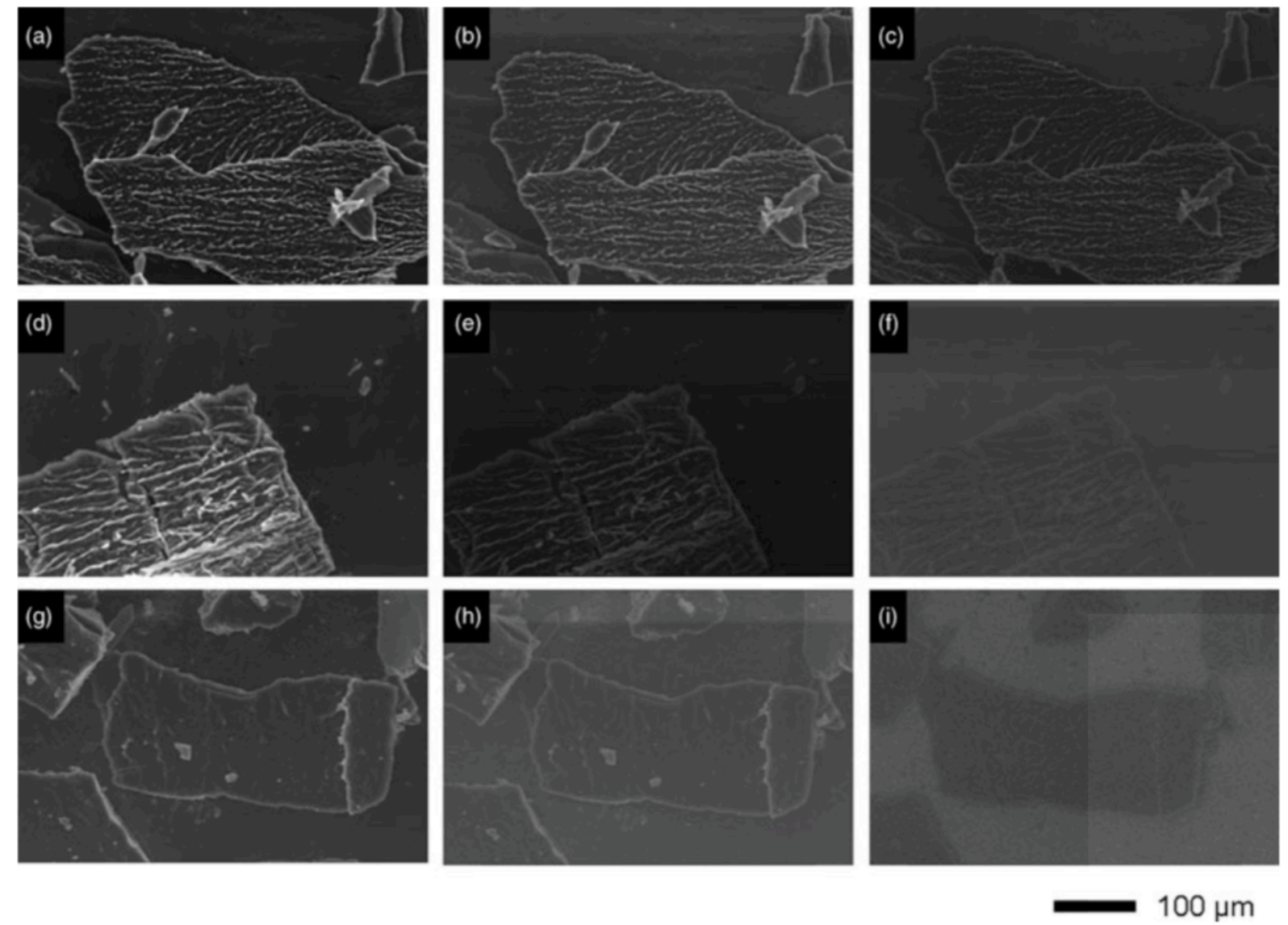

Fig. 6. Evolution of images obtained with three different gases at different temperatures: water (a) at $1000^{\circ} \mathrm{C}$, (b) at $1200^{\circ} \mathrm{C}$ and (c) $1300^{\circ} \mathrm{C} ; \mathrm{N}_{2}$ (d) at $1000^{\circ} \mathrm{C}$, (e) at $1100^{\circ} \mathrm{C}$ and (f) $1250^{\circ} \mathrm{C}$; dry air (g) at $900^{\circ} \mathrm{C}$, (h) at $1050^{\circ} \mathrm{C}$ and (i) at $1200^{\circ} \mathrm{C}$. 

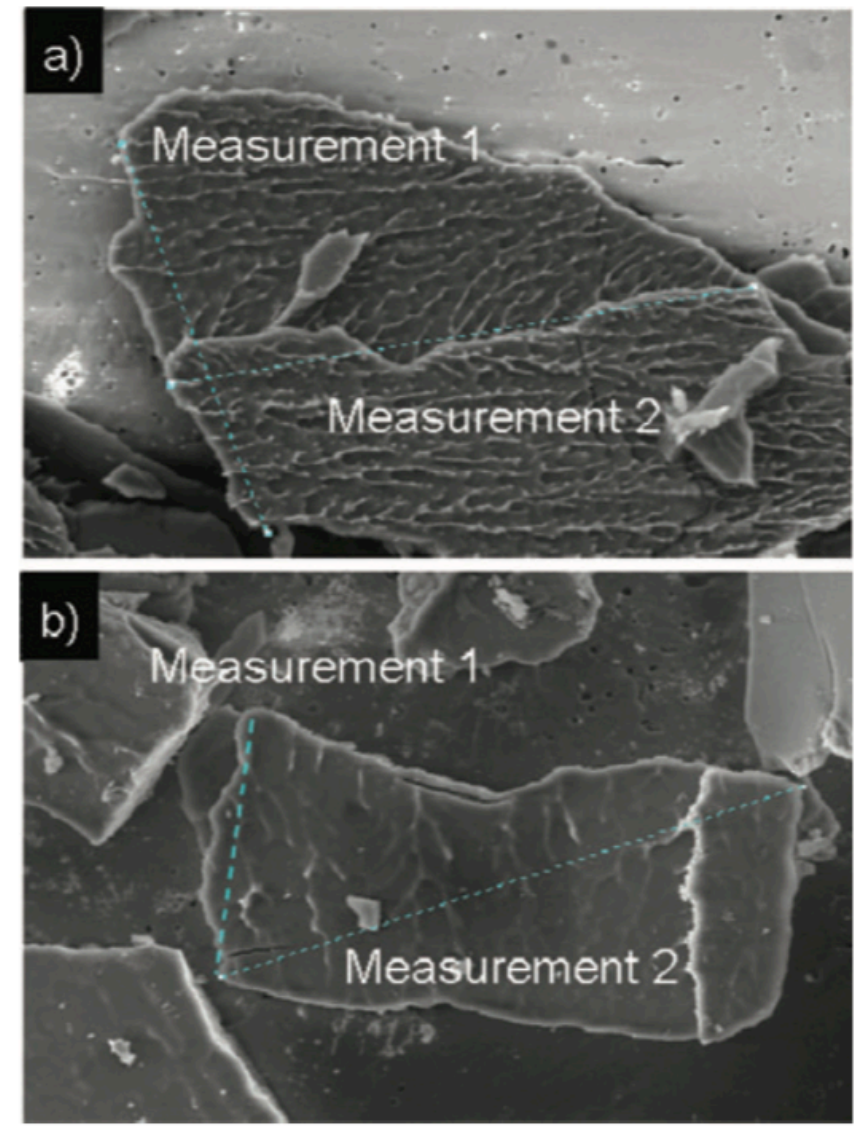

Fig. 7. Measurement of shrinkage of samples treated (a) in water, (b) in dry air. Two directions were measured on both samples to evaluate the shrinkage. 

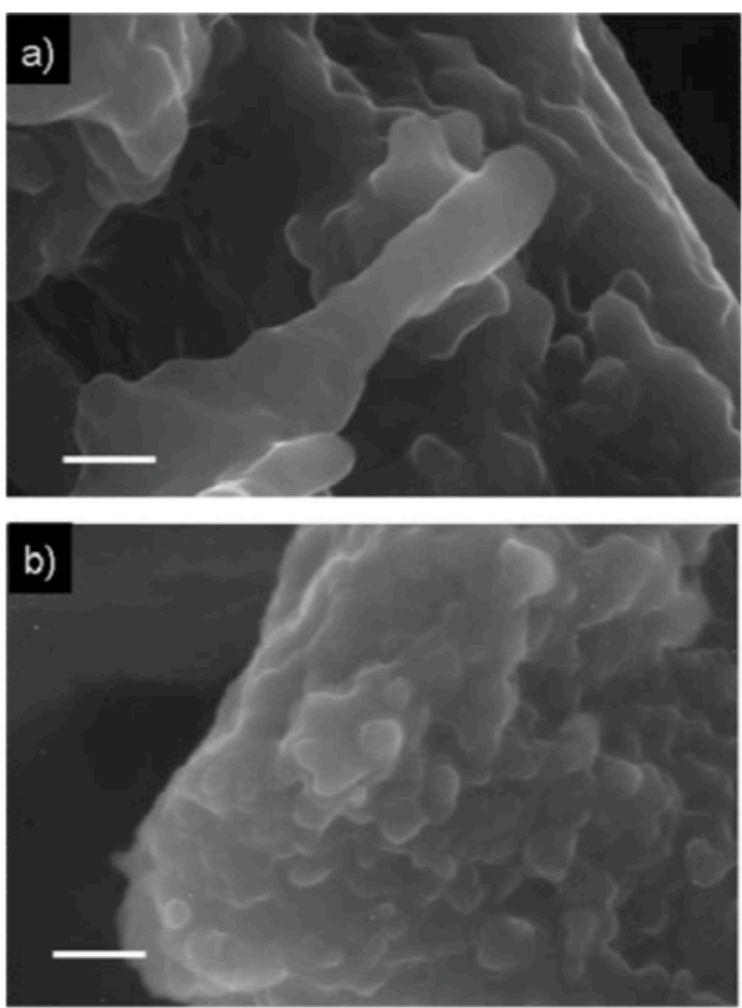

Fig.8. Surfaces of Ceralox green samples after sintering process (a)in dry air and (b) in $\mathrm{N}_{2}$. A glassy surface is observed in both cases. Scale bar length: $2 \mu \mathrm{m}$.

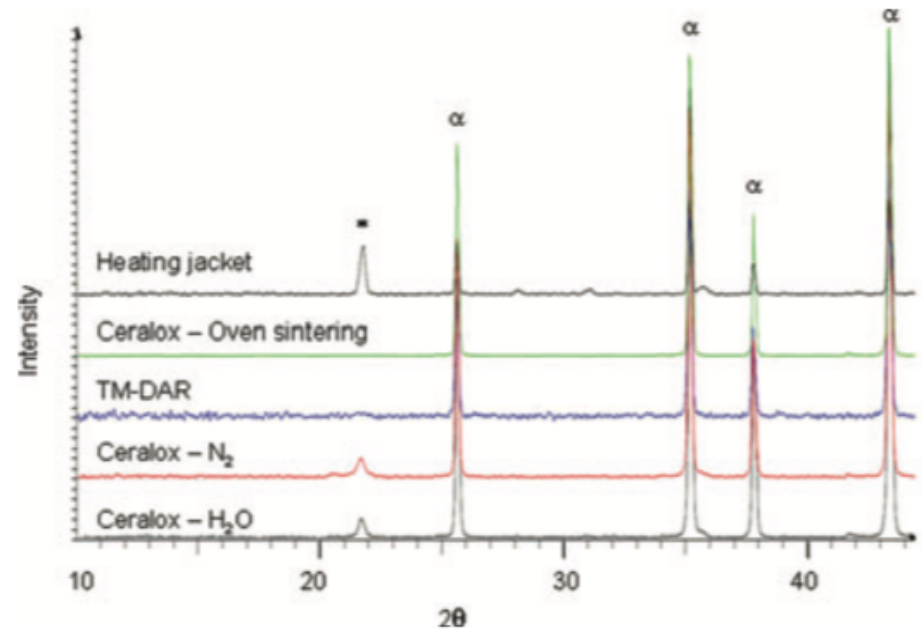

Fig. 9. DRX analyses of Ceralox green samples sintered in water and in N2 inside the microscope or sintered in an oven, of TM-DAR green sample sintered in water inside the microscope, and of a piece of the heating jacket ( $\alpha=$ alpha-alumina; $\left.*=\mathrm{AlPO}_{4}\right)$. 

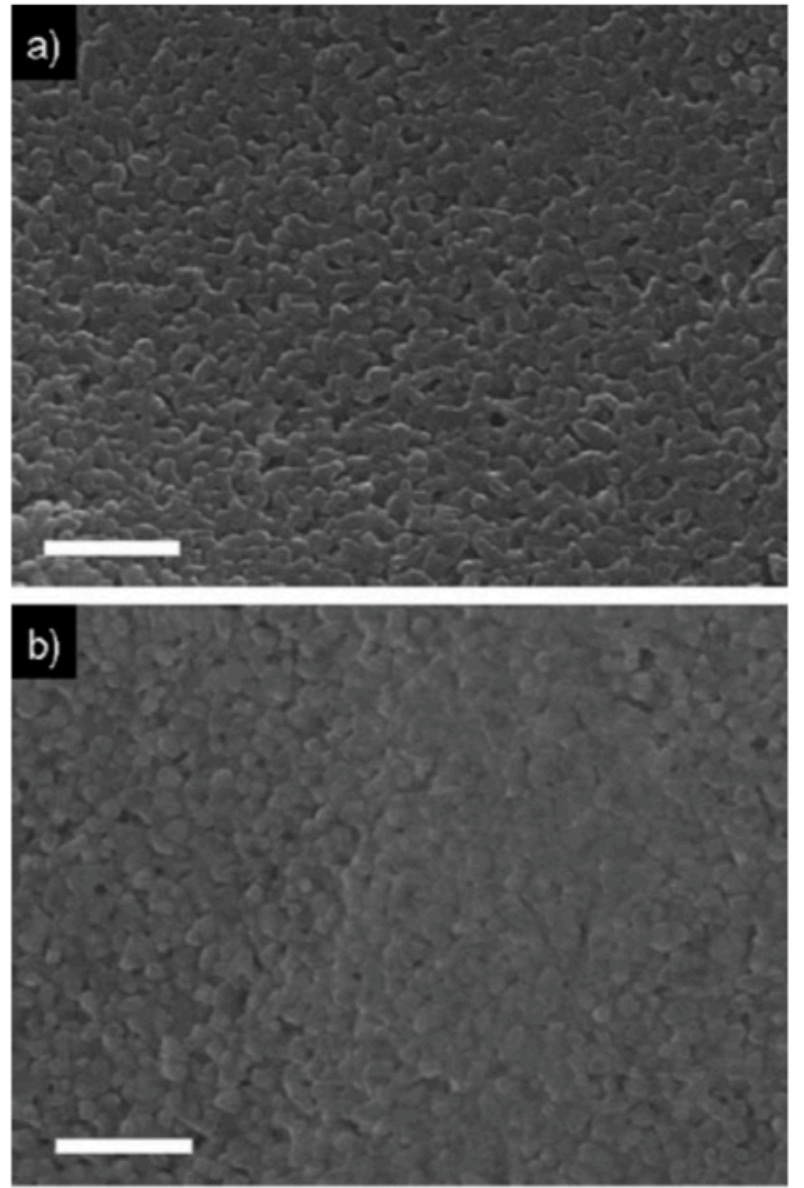

Fig. 10. Structure of TM-DAR after treatment (a) in water and (b) in dry air. Scale bar length: $1 \mu \mathrm{m}$. 